\title{
Identification of critical genes in nucleus pulposus cells isolated from degenerated intervertebral discs using bioinformatics analysis
}

\author{
ZHUANGCHEN ZHU*, GUANG CHEN*, WEI JIAO, DEFENG WANG, \\ YAN CAO, QINGFU ZHANG and JUNQIN WANG \\ Department of Orthopedics, Affiliated Hospital of Taishan Medical University, Tai'an, Shandong 271000, P.R. China
}

Received March 15, 2016; Accepted February 28, 2017

DOI: $10.3892 / \mathrm{mmr} .2017 .6662$

\begin{abstract}
Intervertebral disc (IVD) degeneration is a pathological process, which may lead to lower back pain. The present study aimed to investigate the pathogenesis of IVD degeneration. GSE42611 was downloaded from Gene Expression Omnibus, including 4 nucleus pulposus samples isolated from degenerated IVDs and 4 nucleus pulposus samples separated from normal IVDs. The differentially expressed genes (DEGs) between the degenerated and normal samples were screened using the limma package in $\mathrm{R}$. Functional and pathway enrichment analyses were conducted separately for the upregulated and downregulated genes, using Database for Annotation, Visualization and Integrated Discovery software. In addition, protein-protein interaction (PPI) networks were constructed using the Search Tool for the Retrieval of Interacting Genes database and Cytoscape software. Finally, module analyses were conducted for the PPI networks using the MCODE plug-in in Cytoscape. A total of 558 DEGs were identified in the degenerated nucleus pulposus cells: 253 upregulated and 305 downregulated. Pathway enrichment analysis revealed that downregulated thrombospondin 1 (THBS1) was enriched in extracellular matrix-receptor interaction. Interleukin (IL)-6 in the PPI network for the upregulated genes and vascular endothelial growth factor A (VEGFA) in the PPI network for the downregulated genes had higher degrees. Additionally, four modules ( $\mu \mathrm{M} 1, \mu \mathrm{M} 2, \mu \mathrm{M} 3$ and $\mu \mathrm{M} 4)$ were identified from the PPI network for the upregulated genes. Four modules (dM1,
\end{abstract}

Correspondence to: Dr Zhuangchen Zhu, Department of Orthopedics, Affiliated Hospital of Taishan Medical University, 706 Taishan Street, Taishan, Tai'an, Shandong 271000, P.R. China E-mail: zhuangchen_zhu741@163.com

\section{*Contributed equally}

Key words: intervertebral disc degeneration, differentially expressed genes, functional and pathway enrichment analysis, protein-protein interaction network
$\mathrm{dM} 2, \mathrm{dM} 3$ and dM4) were identified from the PPI network for the downregulated genes. In the dM2 module, collagen genes and integrin subunit $\alpha 4$ (ITGA4) may interact with each other. Additionally, functional enrichment indicated that collagen genes were enriched in extracellular matrix organization. In conclusion, IL-6, VEGFA, THBS1, ITGA4 and collagen genes may contribute to the progression of IVD degeneration. These results suggested that the manipulation of these genes and their products may have potential as a novel therapeutic strategy for the treatment of patients with IVD.

\section{Introduction}

Intervertebral disc (IVD) degeneration, also termed degenerative disc disorder or degenerative disc disease, is a pathological process that may induce acute or chronic lower back pain $(1,2)$. Lower back pain is one of the primary health problems in developed countries (3). The risk factors for disc degeneration include genetic inheritance and environmental risk factors, including smoking cigarettes and repetitive and high mechanical loading (4). IVD degeneration is a rapidly progressing disease without an effective therapeutic method (5). Therefore, it is necessary to explore the mechanisms of IVD degeneration in order to be able to develop a novel treatment scheme.

IVD degeneration and the underlying molecular mechanisms have been previously investigated. The aggrecanases ADAM metallopeptidase with thrombospondin type 1 motif (ADAMTS)-1, -4, -5, -9 and -15 may promote extracellular matrix (ECM) alterations during IVD degeneration, and may be used for preventing IVD degeneration and its morbidity (6). In disc cells, reduced expression of SRY-type high mobility group box 9 (SOX9) may be associated with disc degeneration and disc ageing via inhibition of type II collagen expression (7). The growth differentiation factor-5 (GDF-5) cDNA and the recombinant GDF-5 protein may promote the expression of ECM protein-coding genes in mouse IVD cells (8). Previous studies have detected overexpressed tumor necrosis factor $\alpha(T N F-\alpha)$ and interleukin $(I L)-1$ in aged and degenerative IVDs obtained from human and animal models $(9,10)$. $I L-1$ has been identified to be involved in IVD degeneration via directly inhibiting matrix synthesis and promoting matrix 
degradation (11,12). Cytokines of $I L-1$ and $T N F-\alpha$ may be associated with the pathogenesis of IVD degeneration; however, $I L-1$ may have a greater contribution to IVD degeneration and may be a more suitable therapeutic target for the disease (13).

In 2013, Markova et al (14) established a rat disc organ culture model that mimicked IVD degeneration via culturing rat IVDs in the presence of IL-1 $\beta$, TNF- $\alpha$ and serum-limiting conditions. They obtained 1036 differentially expressed genes (DEGs) between experimental and control groups following gene expression analysis for microarray data. The present study used the data from Markova et al (14) and the DEGs between degenerated and normal nucleus pulposus cells were identified, and their possible functions were predicted using enrichment analysis. Additionally, protein-protein interaction (PPI) networks were visualized and module analysis was conducted to screen for key genes in degenerated nucleus pulposus cells.

\section{Materials and methods}

Microarray data. Microarray data obtained from GSE42611 (http://www.ncbi.nlm.nih.gov/geo/query/acc .cgi?acc $=$ GSE42611), which was downloaded from the database of Gene Expression Omnibus (GEO), were sequenced on the platform of GPL6247 Affymetrix Rat Gene 1.0 ST Array [transcript (gene) version]. GSE42611 included 4 nucleus pulposus samples isolated from degenerated IVDs and 4 nucleus pulposus samples separated from normal IVDs. The procedure that had been used to obtain the rat lumbar disc specimens ( $\mathrm{n}=4$ specimens/group) was as follows, according to the method of Ponnappan et al (8): Whole lumbar IVDs with endplates had been dissected and preserved in organ culture. Lumbar discs in the experimental group had been cultivated in Dulbecco's modified Eagle's medium (DMEM) containing $100 \mathrm{ng} / \mathrm{ml} \mathrm{TNF}-\alpha, 10 \mathrm{ng} / \mathrm{ml} \mathrm{IL}-1 \beta, 50 \mu \mathrm{g} / \mathrm{ml}$ L-ascorbate, $40 \mathrm{mM} \mathrm{NaCl}, 1 \%$ fetal bovine serum (FBS), antibiotics and antimycotics. Lumbar discs in the control group had been cultured in DMEM containing $50 \mu \mathrm{g} / \mathrm{ml} \mathrm{L}$-ascorbate, $40 \mathrm{mM}$ $\mathrm{NaCl}, 10 \%$ FBS and antibiotics without cytokines. The discs had been cultured for a total of 10 days (14). GSE42611 used in this study was downloaded from a public database; therefore, patient consent or ethics committee approval were not required.

Data preprocessing and DEGs screening. GSE42611 was downloaded and the microarray data was preprocessed using the Affy package (15) in R. The process of data preprocessing included background correction, quantile normalization, summarization and probe ID to gene symbol transformation. Linear models for microarray data in the limma package (16) in $\mathrm{R}$ were used to analyze the DEGs between degenerated and normal nucleus pulposus cells. P-values of the DEGs were calculated separately and adjusted using the t-test method and the Benjamini \& Hochberg method (17). P $<0.05$ and $\mid \log _{2}$ fold-change (FC) $\mid>1$ were used as the thresholds.

Functional and pathway enrichment analysis. The Database for Annotation, Visualization and Integrated Discovery (DAVID; david.abcc.ncifcrf.gov) software was used to interpret functions of extensive genes obtained from previous genome studies (18). The Gene Ontology database (GO; www.geneontology.org) contained structured ontologies or vocabularies that depict basic characteristics of genes and gene products (19). The Kyoto Encyclopedia of Genes and Genomes database (KEGG; www.genome.jp/kegg/) synthesizes information of biological systems from genomic, chemical and systemic functional aspects (20). Using the DAVID software, functional and pathway enrichment analyses were conducted separately, for upregulated and downregulated genes. $\mathrm{P} \leq 0.05$ and $>2$ enriched genes were set as the thresholds.

PPI network construction and module analysis. The Search Tool for the Retrieval of Interacting Genes (STRING; string-db.org) database provide comprehensive and easily accessible interaction information derived from experiments and predictions (21). Cytoscape software (www.cytoscape .org) was used to integrate high-throughput expression data and biomolecular interaction networks into a unified framework (22). The PPIs obtained for the DEGs were searched using the STRING database (21), with the required confidence (combined score) $>0.4$ as the threshold. Using Cytoscape software version 2.8 (22), the PPIs were used to established a PPI network. In the network, the proteins were termed nodes and the number of edges involved were their degrees. Finally, the MCODE plug-in (23) in Cytoscape was used to perform module analysis of the PPI networks. The parameters were set at the default thresholds.

\section{Results}

DEG analysis. $\mathrm{P}<0.05$ and $\mid \log _{2} \mathrm{FCl}>1$ were set as thresholds and the DEGs between degenerated and normal nucleus pulposus cells were analyzed. There were 558 DEGs identified in the degenerated nucleus pulposus cells compared with normal nucleus pulposus cells, including 253 upregulated and 305 downregulated genes. There were more downregulated genes compared with upregulated genes.

Functional and pathway enrichment analysis. The upregulated genes in the degenerated nucleus pulposus cells were significantly enriched in $255 \mathrm{GO}$ terms and 9 KEGG pathways. The top 10 functions are presented in Table IA, including response to wounding $\left(\mathrm{P}=2.35 \times 10^{-8}\right)$, inflammatory response $\left(\mathrm{P}=5.99 \times 10^{-8}\right)$ and response to organic substance $\left(\mathrm{P}=1.56 \times 10^{-7}\right)$.

The downregulated genes in the degenerated nucleus pulposus cells were significantly enriched in $263 \mathrm{GO}$ terms and 10 KEGG pathways. The top 10 functions included $M$ phase $\left(\mathrm{P}=9.18 \times 10^{-12}\right)$, cell cycle phase $\left(\mathrm{P}=2.81 \times 10^{-10}\right)$ and response to steroid hormone stimulus $\left(\mathrm{P}=2.95 \times 10^{-9}\right.$; Table IB).

Additionally, the upregulated genes were significantly enriched in cytokine-cytokine receptor interaction $\left(\mathrm{P}=2.86 \times 10^{-4}\right)$, apoptosis $\left(\mathrm{P}=3.95 \times 10^{-4}\right)$ and chemokine $\left(\mathrm{P}=1.60 \times 10^{-3}\right.$; Table IIA) signaling pathways.

The pathways enriched for the downregulated genes included ECM-receptor interaction $\left[\mathrm{P}=1.17 \times 10^{-11}\right.$, involving thrombospondin $1\left(\right.$ THBS1)], focal adhesion $\left(\mathrm{P}=1.90 \times 10^{-9}\right)$ and hematopoietic cell lineage ( $\mathrm{P}=3.12 \times 10^{-3}$; Table IIB).

PPI network construction and module analysis. PPI networks were constructed by Cytoscape software following a PPI 


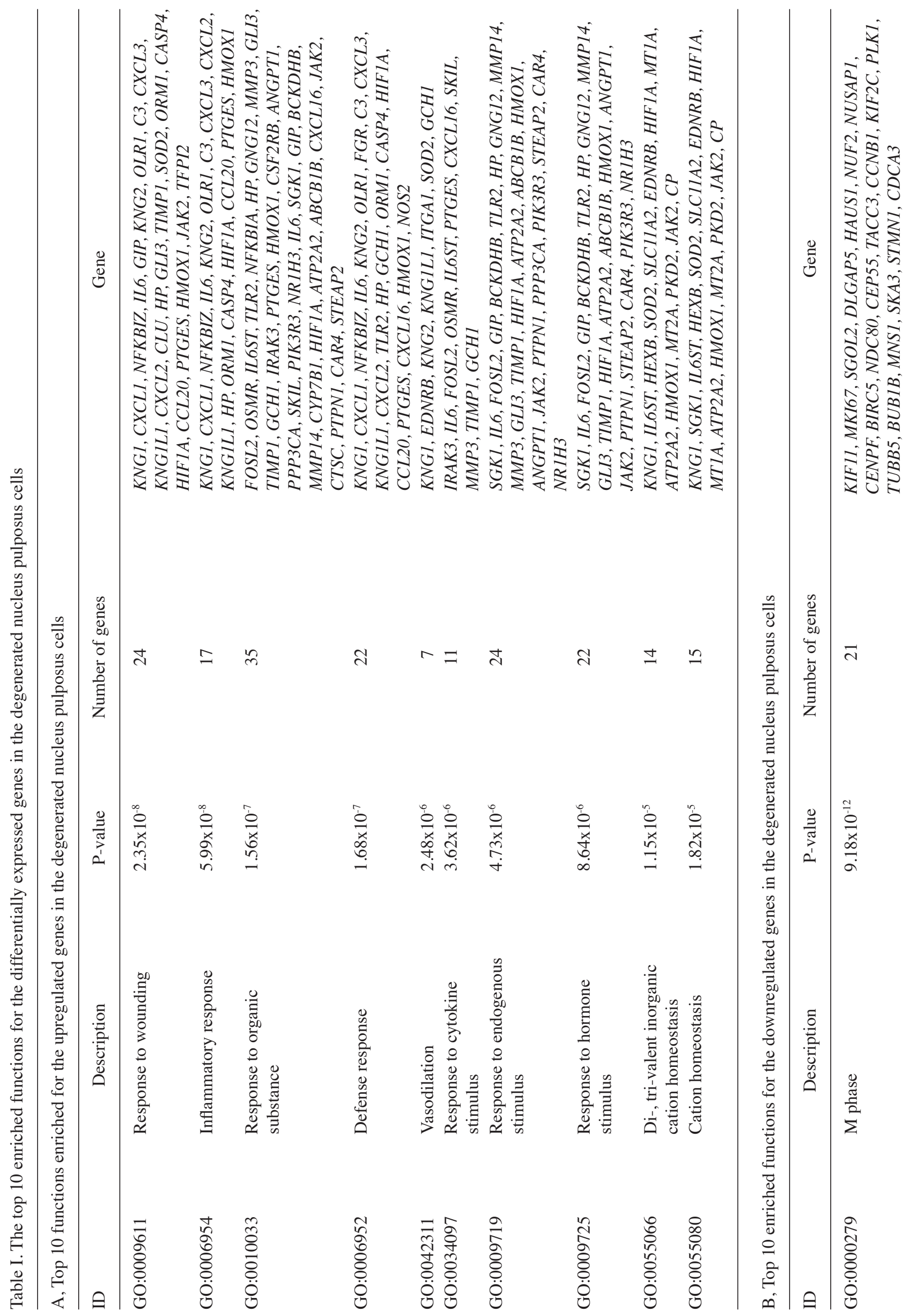




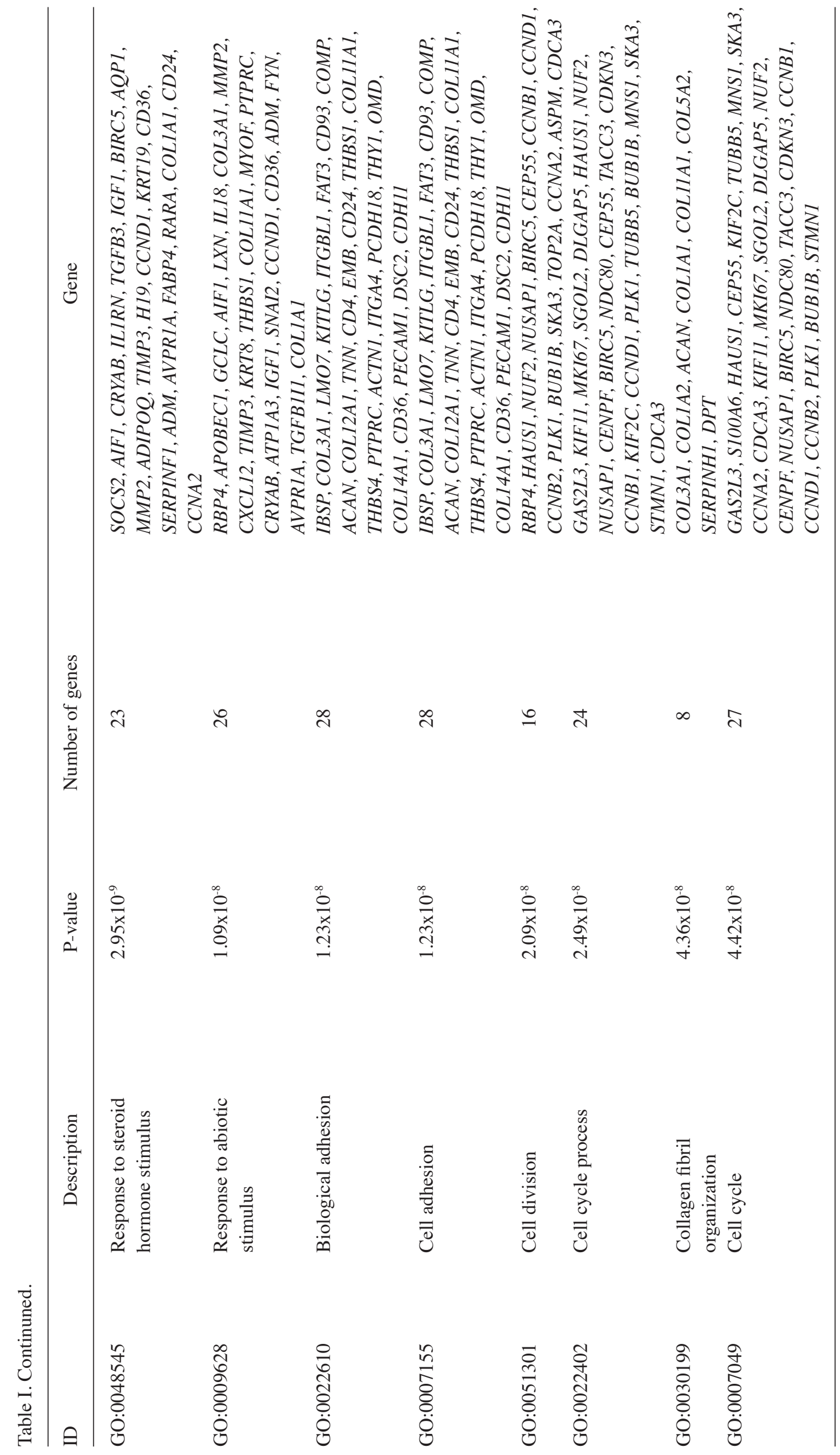




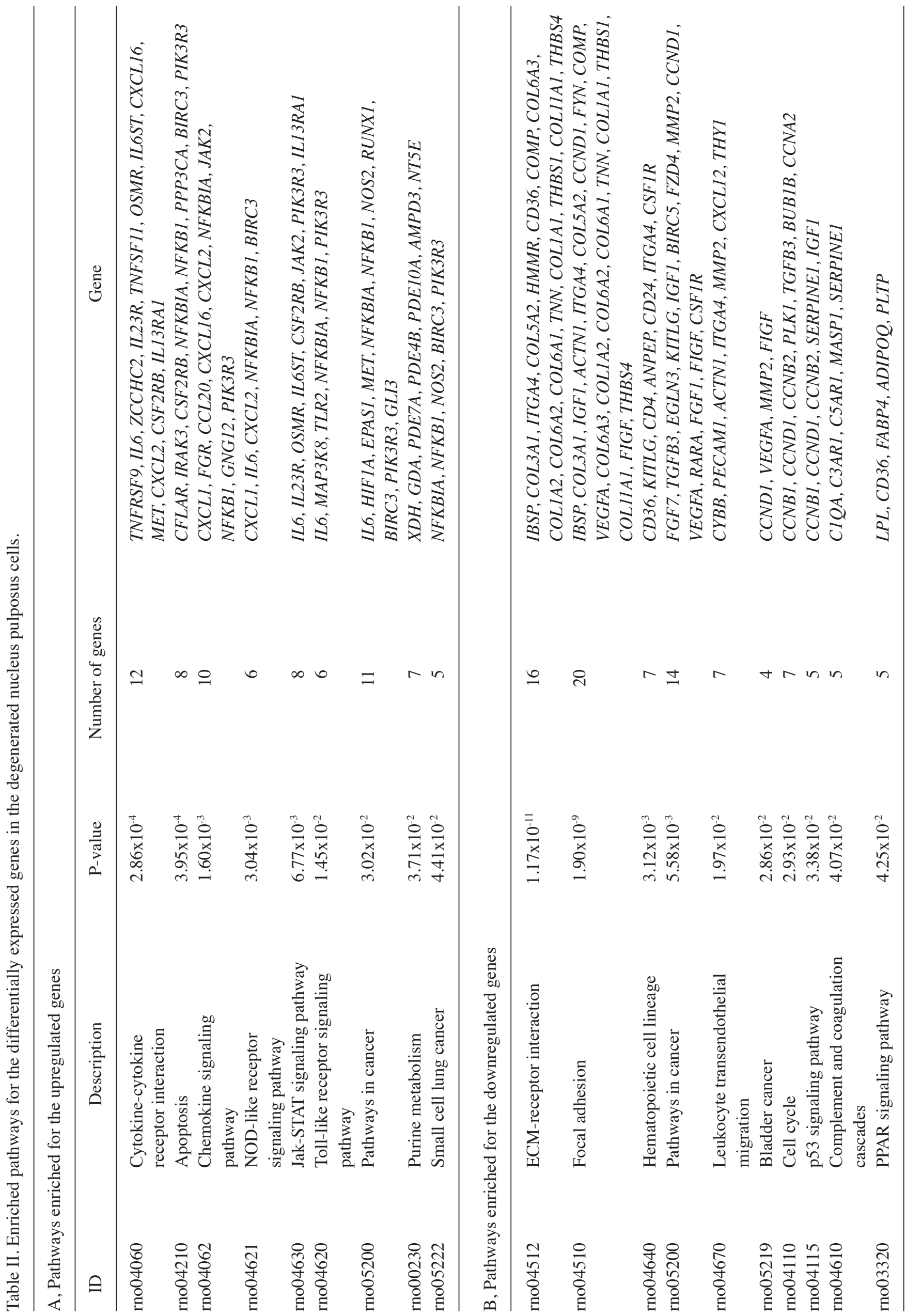




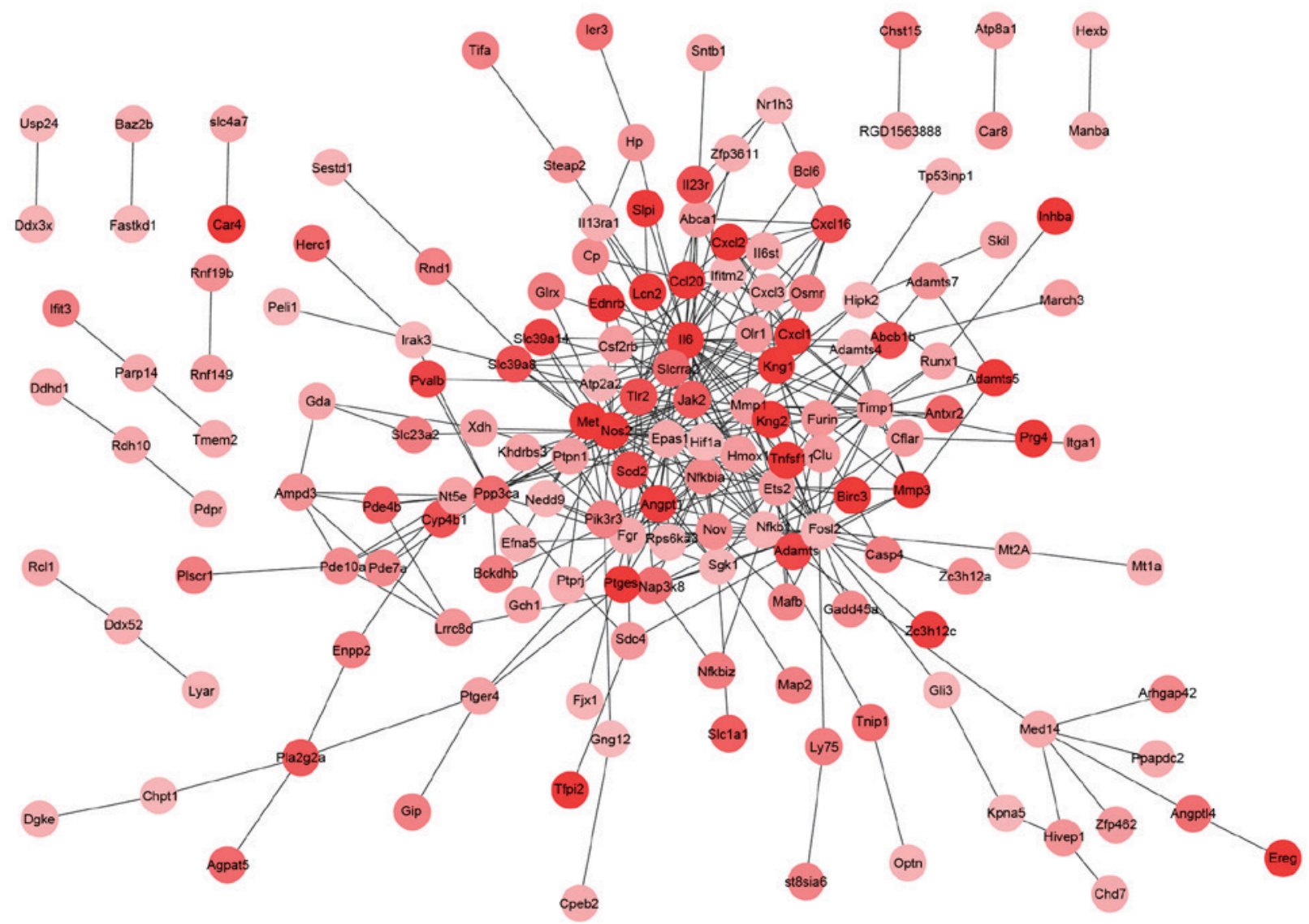

Figure 1. Protein-protein interaction network constructed for the upregulated genes.

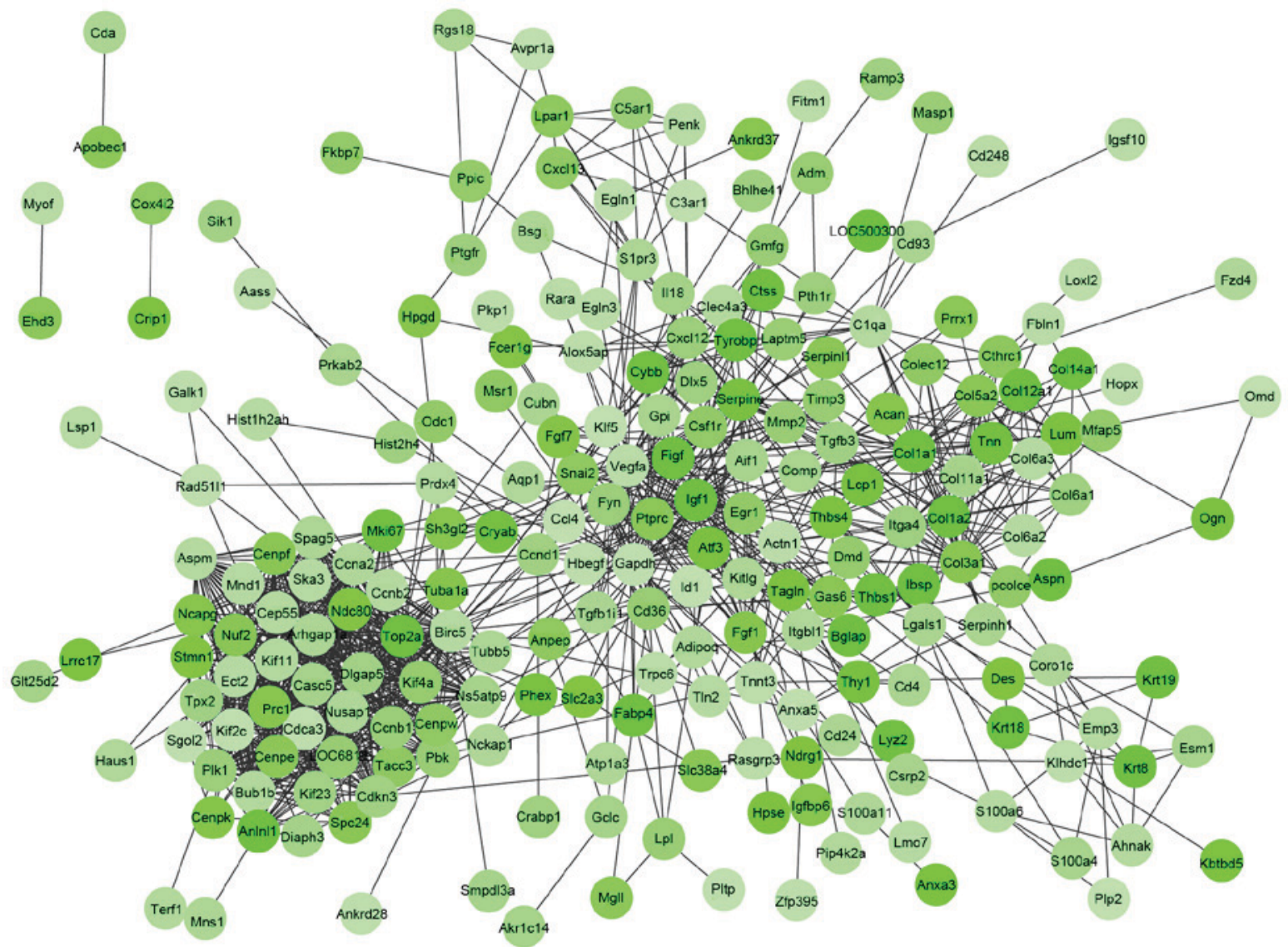

Figure 2. Protein-protein interaction network constructed for the downregulated genes. 
$\mu \mathrm{M} 1$

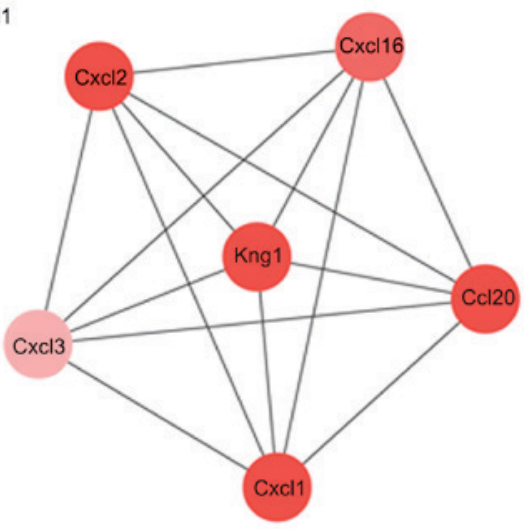

$\mu \mathrm{M} 3$

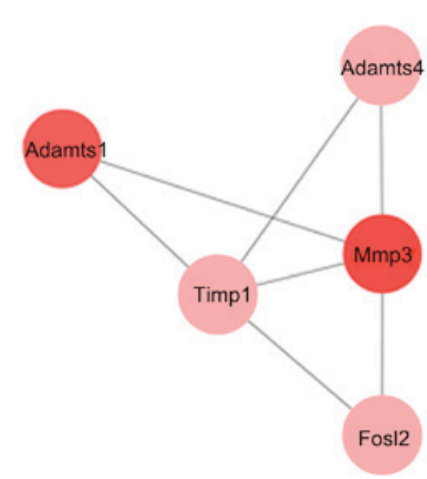

$\mu \mathrm{M} 2$

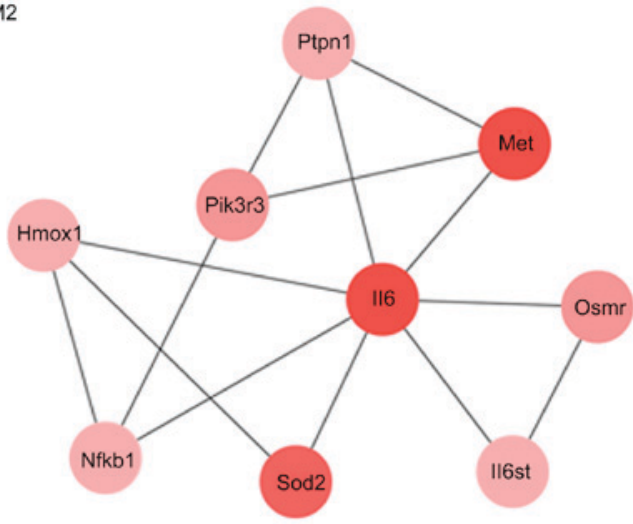

$\mu \mathrm{M} 4$

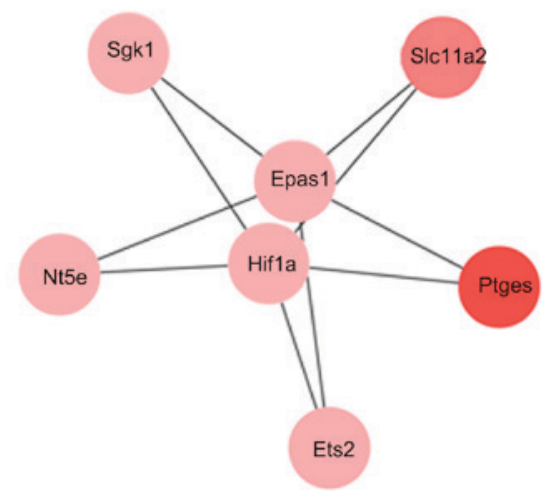

Figure 3. Four modules ( $\mu \mathrm{M} 1, \mu \mathrm{M} 2, \mu \mathrm{M} 3$ and $\mu \mathrm{M} 4$ ) identified from the protein-protein interaction network constructed for the upregulated genes.

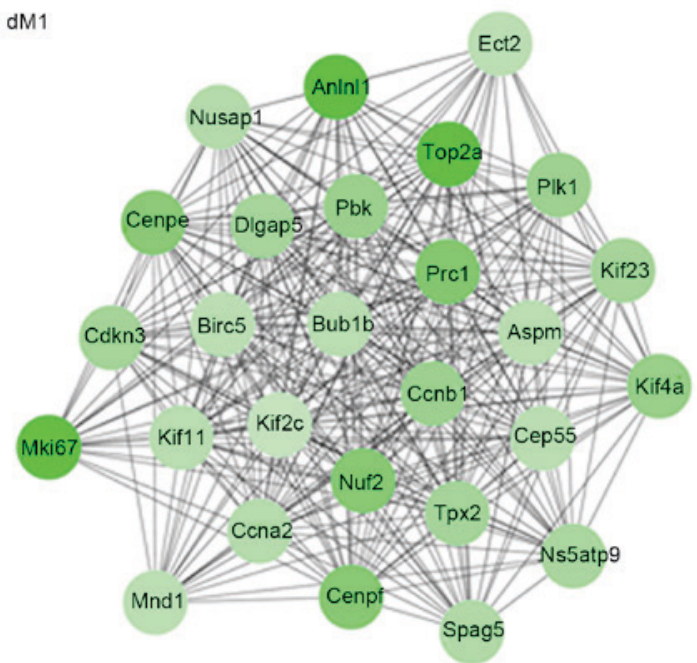

$\mathrm{dM} 3$

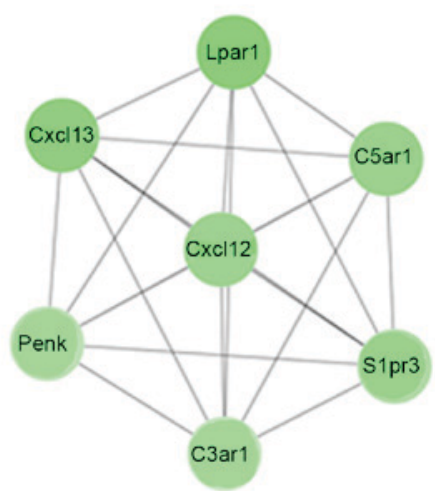

$\mathrm{dM} 2$

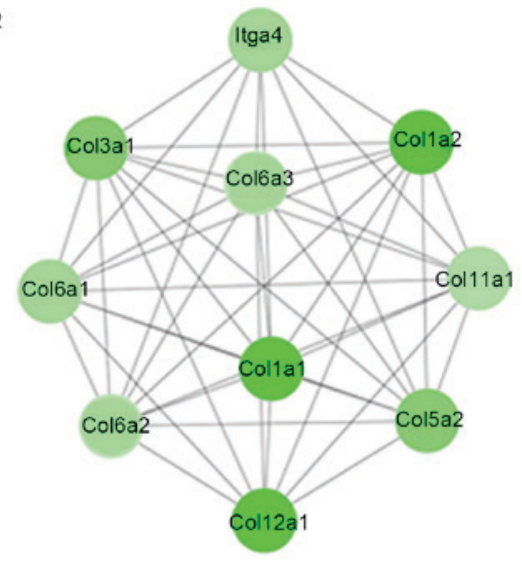

$\mathrm{dM} 4$

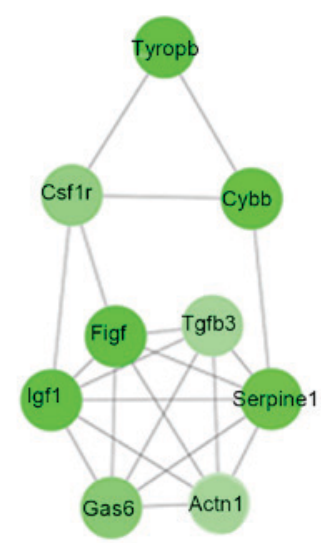

Figure 4. Four modules (dM1, dM2, dM3 and dM4) identified from the protein-protein interaction network constructed for the downregulated genes. 


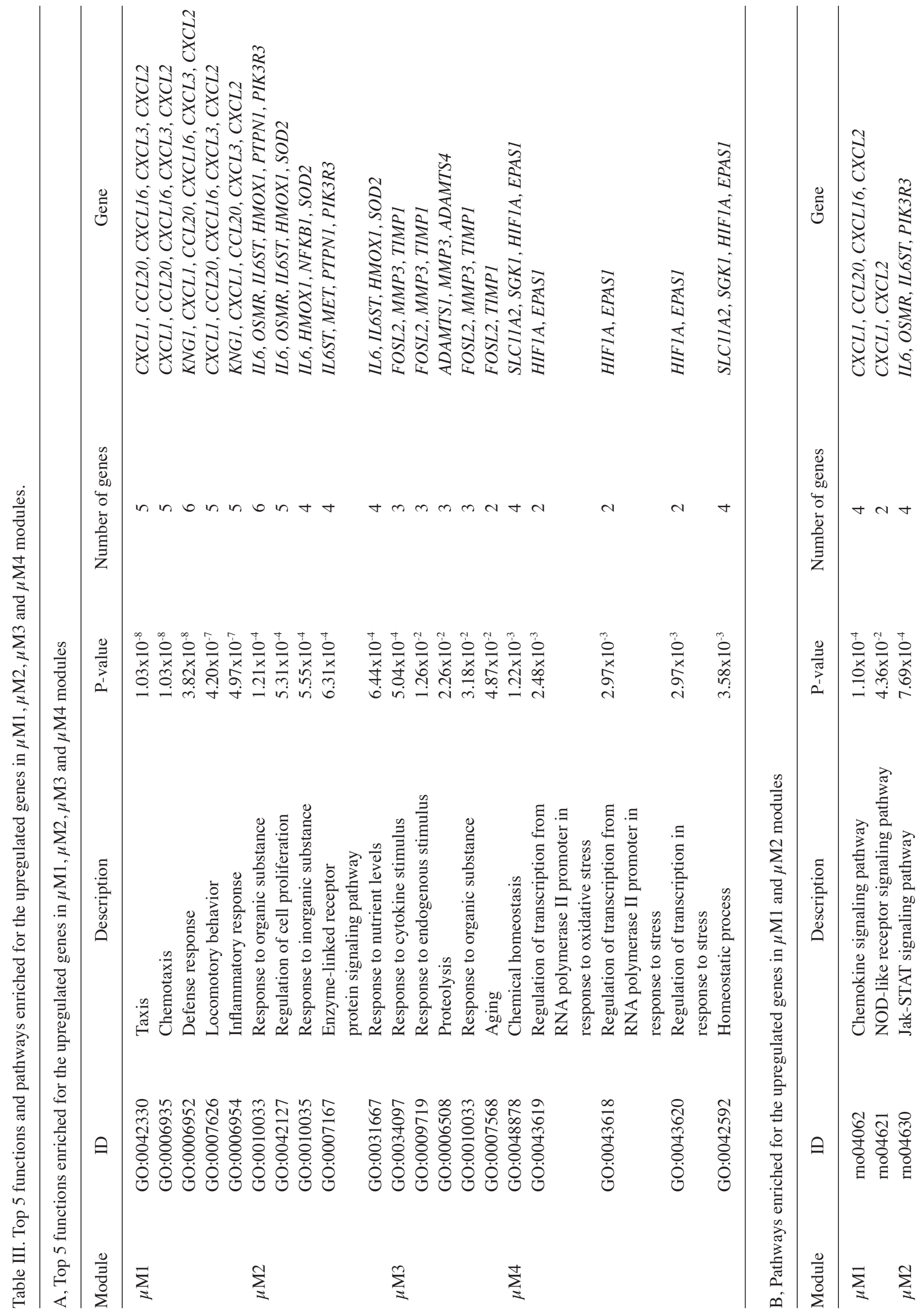


search of the DEGs. The PPI networks for the upregulated (Fig. 1) and the downregulated (Fig. 2) genes separately had 360 and 1,112 interactions. Notably, IL-6 (degree=39) in the PPI network for the upregulated genes and vascular endothelial growth factor A (VEGFA; degree=37) in the PPI network for the downregulated genes had higher degrees. Using the MCODE plug-in in Cytoscape, four modules $(\mu \mathrm{M} 1, \mu \mathrm{M} 2$, $\mu \mathrm{M} 3$ and $\mu \mathrm{M} 4)$ were identified from the PPI network for the upregulated genes (Fig. 3). Meanwhile, four modules (dM1, dM2, dM3 and dM4) were identified from the PPI network for the downregulated genes (Fig. 4). It is of note that collagen, type I, $\alpha 1$ (COL1A1), COL1A2, COL3A1, COL5A2, COL6A1, COL6A2, COL6A3, COL11A1, COL12A1 and integrin $\alpha 4$ (ITGA4) may interact with each other in the dM2 module.

The top 5 functions enriched for the upregulated genes in modules included taxis $\left(\mu \mathrm{M} 1 ; \mathrm{P}=1.03 \times 10^{-8}\right)$, response to organic substance $\left(\mu \mathrm{M} 2 ; \mathrm{P}=1.21 \times 10^{-4}\right)$, response to cytokine stimulus $\left(\mu \mathrm{M} 3 ; \mathrm{P}=5.04 \times 10^{-4}\right)$ and chemical homeostasis $(\mu \mathrm{M} 4$, $\mathrm{P}=1.22 \times 10^{-3}$; Table IIIA). The pathways enriched for the upregulated genes in modules included the chemokine signaling pathway $\left(\mu \mathrm{M} 1 ; \mathrm{P}=1.10 \times 10^{-4}\right)$ and the Jak-STAT signaling pathway ( $\mu \mathrm{M} 2 ; \mathrm{P}=7.69 \times 10^{-4}$; Table IIIB). Additionally, the top 5 functions enriched for the downregulated genes in modules, included $\mathrm{M}$ phase $\left(\mathrm{dM} 1 ; \mathrm{P}=2.70 \times 10^{-16}\right)$, extracellular matrix organization (dM2; $\mathrm{P}=1.79 \times 10^{-7}$, including COL3A1, COL1A2, COL1A1, COL11A1 and COL5A2), G-protein coupled receptor protein signaling pathway $\left(\mathrm{dM} 3 ; \mathrm{P}=7.27 \times 10^{-4}\right)$ and wound healing ( $\mathrm{dM} 4 ; \mathrm{P}=1.56 \times 10^{-4}$; Table IVA). The pathways enriched for the downregulated genes in modules included cell cycle (dM1; $\left.\mathrm{P}=4.40 \times 10^{-5}\right)$, ECM-receptor interaction (dM2; $\mathrm{P}=1.37 \times 10^{-15}$, including COL3A1, COL6A3, COL1A2, COL6A2, COL6A1, ITGA4, COL1A1, COL11A1 and COL5A2) and neuroactive ligand-receptor interaction (dM3; $\mathrm{P}=9.49 \times 10^{-4}$; Table IVB).

\section{Discussion}

The present study identified a total of 558 DEGs in degenerated nucleus pulposus cells compared with normal nucleus pulposus cells, including 253 upregulated and 305 downregulated genes. Using the MCODE plug-in in Cytoscape, four modules $(\mu \mathrm{M} 1, \mu 0 \mathrm{M} 2, \mu \mathrm{M} 3$ and $\mu \mathrm{M} 4)$ were identified from the PPI network for the upregulated genes. Additionally, four modules (dM1, dM2, dM3 and dM4) were identified from the PPI network for the downregulated genes.

A previous study demonstrated that genetic variations of IL- 6 may be associated with IVD degeneration, accompanied by sciatica (24). VEGFA was overexpressed in the nucleus pulposus and affects the survival of nucleus pulposus cells in an autocrine/paracrine manner (25). Injuries of IVDs may lead to increased VEGF levels, indicating that VEGF may be associated with discogenic back pain (26). Under co-culture conditions, VEGF induction may contribute to neo-vascularization of IVD tissue and may function in the resorption of herniated discs (27). The findings of the present study indicated that IL-6 (degree=39) in the PPI network for the upregulated genes and VEGFA (degree=37) in the PPI network for the downregulated genes had higher degrees. Therefore, IL 6 and VEGFA may be key genes involved in IVD degeneration. A previous study observed the immunolocalization of THBS in 


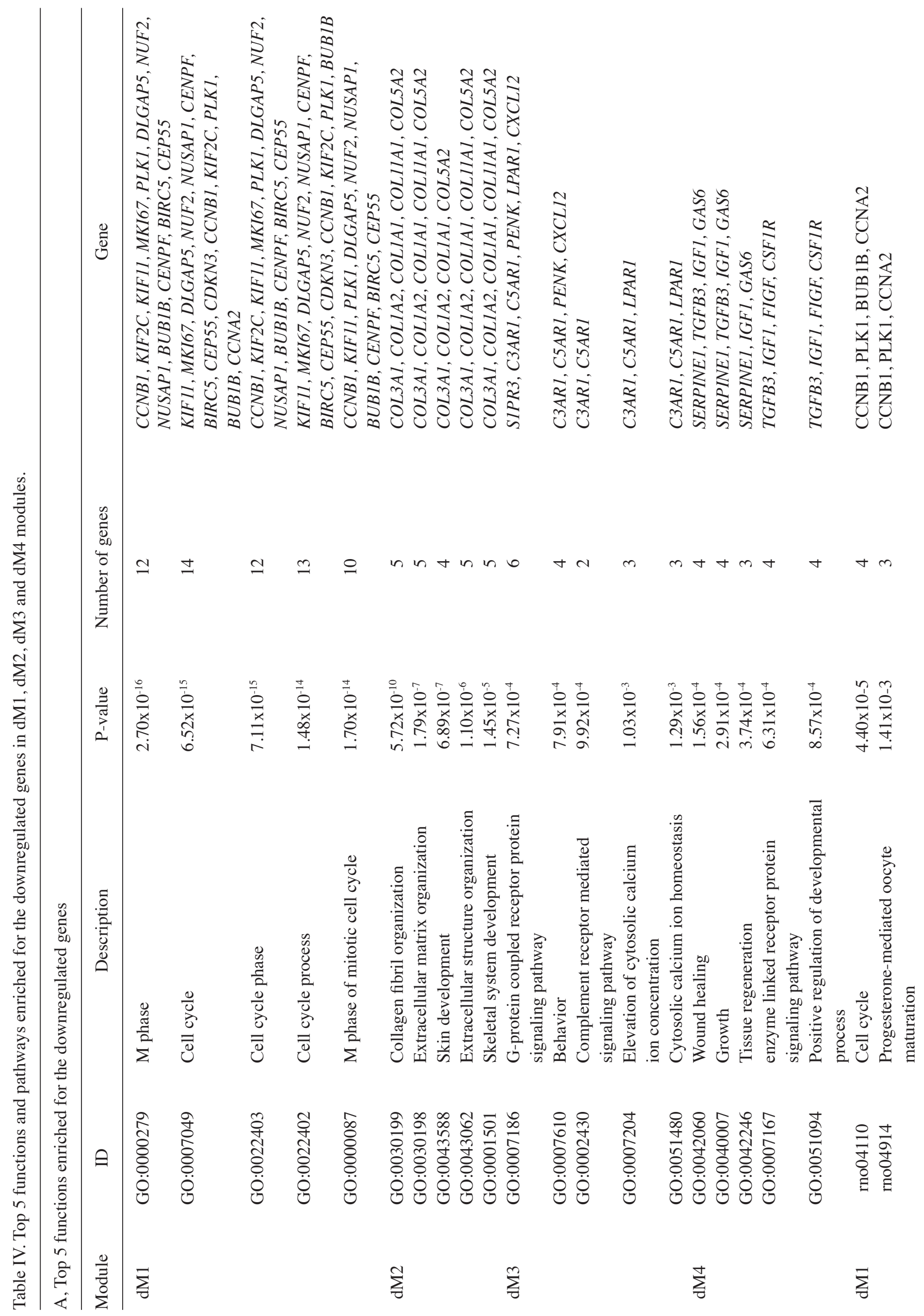


human IVD (28). THBS1 and THBS2 are promising susceptibility genes in lumbar-disc herniation (LDH) that mediate the expression levels of matrix metalloproteinases (MMPs) 2 and 9, which are critical effectors of ECM remodeling (29). Mice with THBS1 or THBS2 deficiency exhibit abnormal spine curvature (30). Pathway enrichment performed in the present study revealed that downregulated THBS1 was enriched in ECM-receptor interactions, suggesting that THBS1 may have an important role in IVD degeneration.

The sequence variation of the regulatory region of COL1A1 is closely associated with lumbar disc disease (LDD) in young military recruits who are newly diagnosed (31). Ribosomal protein L8, ribosomal protein S16 and ribosomal protein S23 have been identified to contribute to protein synthesis, and COL3A1 was involved in skeletal system processes in disc degeneration (DD), indicating that they may be used for diagnosis and therapy of DD (32). Polymorphisms of the COL9 and $C O L 11$ genes contribute to the progression of degenerative lumbar spinal stenosis (33). COL11A1 expression level was reduced in the IVD of patients with $\mathrm{LDH}$ and it had a negative association with the severity of disc degeneration in patients with LDH (34). In the dM2 module identified by the present study, COL1A1, COL1A2, COL3A1, COL5A2, COL6A1, COL6A2, COL6A3, COL11A1, COL12A1 and ITGA4 may interact with each other. Functional enrichment indicated that collagen genes were enriched in ECM organization. Therefore, collagen genes may contribute to the progression of IVD degeneration. Additionally, ITGA4 may also be implicated in IVD degeneration via interaction with collagen genes.

In conclusion, the present study investigated the underlying mechanisms of IVD degeneration via bioinformatics analysis. A total 558 DEGs were screened in the degenerated nucleus pulposus cells. IL6, VEGFA, THBS1, ITGA4 and collagen genes may be involved in the progression of IVD degeneration. These results suggested that the manipulation of these genes and their products may have potential as a novel therapeutic strategy for the treatment of patients with IVD. However, these findings were obtained by bioinformatics prediction and require further confirmation via further experimental studies.

\section{Acknowledgements}

The present study was supported by the Shandong Province Pharmaceutical Technology Development Program (grant no. 2015-261), the Projects of Medical and Health Technology Development Program in Shandong Province, China (grant no. 2014WS0502), the Taishan Medical University Cultivate High-level Task Projects (grant no. 2014GCC02) and the Projects of Health Science and Technology Association in Shandong Province, China (grant no. 2016BJ0009).

\section{References}

1. Sakai D, Mochida J, Yamamoto Y, Nomura T, Okuma M, Nishimura K, Nakai T, Ando K and Hotta T: Transplantation of mesenchymal stem cells embedded in Atelocollagen gel to the intervertebral disc: A potential therapeutic model for disc degeneratio. Biomaterials 24: 3531-3541, 2003.

2. Le Maitre CL,Pockert A, Buttle DJ, Freemont AJ and Hoyland JA: Matrix synthesis and degradation in human intervertebral disc degeneration. Biochem Soc Trans 35: 652-655, 2007. 
3. Richardson SM, Walker RV, Parker S, Rhodes NP, Hunt JA, Freemont AJ and Hoyland JA: Intervertebral disc cell-mediated mesenchymal stem cell differentiation. Stem Cells 24: 707-716, 2006.

4. Battié MC, Videman T and Parent E: Lumbar disc degeneration: Epidemiology and genetic influences. Spine 29: 2679-2690, 2004.

5. Sakai D, Mochida J, Iwashina T, Hiyama A, Omi H, Imai M, Nakai T, Ando K and Hotta T: Regenerative effects of transplanting mesenchymal stem cells embedded in atelocollagen to the degenerated intervertebral disc. Biomaterials 27: 335-345, 2006.

6. Pockert AJ, Richardson SM, Le Maitre CL, Lyon M, Deakin JA, Buttle DJ, Freemont AJ and Hoyland JA: Modified expression of the ADAMTS enzymes and tissue inhibitor of metalloproteinases 3 during human intervertebral disc degeneration. Arthritis Rheum 60: 482-491, 2009.

7. Gruber HE, Norton HJ, Ingram JA and Hanley EN Jr: The SOX9 transcription factor in the human disc: Decreased immunolocalization with age and disc degeneration. Spine (Phila Pa 1976) 30: 625-630, 2005

8. Ponnappan RK, Markova DZ, Antonio PJ, Murray HB, Vaccaro AR, Shapiro IM, Anderson DG, Albert TJ and Risbud MV: An organ culture system to model early degenerative changes of the intervertebral disc. Arthritis Res Ther 13: R171, 2011.

9. Weiler C, Nerlich AG, Bachmeier BE and Boos N: Expression and distribution of tumor necrosis factor alpha in human lumbar intervertebral discs: A study in surgical specimen and autopsy controls. Spine (Phila Pa 1976) 30: 44-54, 2005.

10. Bachmeier BE, Nerlich AG, Weiler C, Paesold G, Jochum M and Boos N: Analysis of tissue distribution of TNF-alpha, TNF-alpha-receptors and the activating TNF-alpha-converting enzyme suggests activation of the TNF-alpha system in the aging intervertebral disc. Ann N Y Acad Sci 1096: 44-54, 2007.

11. Le Maitre CL, Freemont AJ and Hoyland JA: The role of interleukin-1 in the pathogenesis of human intervertebral disc degeneration. Arthritis Res Ther 7: R732-R745, 2005.

12. Hoyland J, Le Maitre $C$ and Freemont A: Investigation of the role of IL-1 and TNF in matrix degradation in the intervertebral disc. Rheumatology (Oxford) 47: 809-814, 2008.

13. Le Maitre CL, Hoyland JA and Freemont AJ: Catabolic cytokine expression in degenerate and herniated human intervertebral discs: IL-1beta and TNFalpha expression profile. Arthritis Res Ther 9: R77, 2007

14. Markova DZ, Kepler CK, Addya S, Murray HB, Vaccaro AR, Shapiro IM, Anderson DG, Albert TJ and Risbud MV: An organ culture system to model early degenerative changes of the intervertebral disc II: Profiling global gene expression changes. Arthritis Res Ther 15: R121, 2013.

15. Gautier L, Cope L, Bolstad BM and Irizarry RA: affy-analysis of Affymetrix GeneChip data at the probe level. Bioinformatics 20 : 307-315, 2004.

16. Smyth GK: Limma: Linear Models for Microarray Data. In: Bioinformatics and Computational Biology Solutions Using R and Bioconductor Springer, pp397-420, 2005.

17. Benjamini $\mathrm{Y}$ and Hochberg Y: Controlling the false discovery rate: A practical and powerful approach to multiple testing. J Royal Statistical Soci 57: 289-300, 1995.

18. Huang DW, Sherman BT, Tan Q, Kir J, Liu D, Bryant D, Guo Y, Stephens R, Baseler MW, Lane HC and Lempicki RA: DAVID bioinformatics resources: Expanded annotation database and novel algorithms to better extract biology from large gene lists. Nucleic Acids Res 35: W169-W175, 2007.

19. Carbon S, Ireland A, Mungall CJ, Shu S, Marshall B and Lewis S; AmiGO Hub; Web Presence Working Group: AmiGO: Online access to ontology and annotation data. Bioinformatics 25 288-289, 2009
20. Kanehisa M, Araki M, Goto S, Hattori M, Hirakawa M, Itoh M, Katayama T, Kawashima S, Okuda S, Tokimatsu T and Yamanishi Y: KEGG for linking genomes to life and the environment. Nucleic Acids Res 36 (Database issue): D480-D484, 2008.

21. Szklarczyk D, Franceschini A, Kuhn M, Simonovic M, Roth A, Minguez P, Doerks T, Stark M, Muller J, Bork P, et al: The STRING database in 2011: Functional interaction networks of proteins, globally integrated and scored. Nucleic Acids Res 39 (Database issue): D561-D568, 2011.

22. Shannon P, Markiel A, Ozier O, Baliga NS, Wang JT, Ramage D, Amin N, Schwikowski B and Ideker T: Cytoscape: A software environment for integrated models of biomolecular interaction networks. Genome Res 13: 2498-2504, 2003.

23. Bader GD and Hogue CW: An automated method for finding molecular complexes in large protein interaction networks. BMC bioinformatics 4: 2, 2003

24. Noponen-Hietala N, Virtanen I, Karttunen R, Schwenke S, Jakkula E, Li H, Merikivi R, Barral S, Ott J, Karppinen J and Ala-Kokko L: Genetic variations in IL6 associate with intervertebral disc disease characterized by sciatica. Pain 114: 186-194, 2005.

25. Fujita N, Imai J, Suzuki T, Yamada M, Ninomiya K, Miyamoto K, Iwasaki R, Morioka H, Matsumoto M, Chiba K, et al: Vascular endothelial growth factor-A is a survival factor for nucleus pulposus cells in the intervertebral disc. Biochem Biophys Res Commun 372: 367-372, 2008

26. Sato J, Sakuma Y, Yamauchi K, Orita S, Kubota G, Oikawa Y, Inage K, Sainoh T, Fujimoto K, Takahashi K, et al: Elevated VEGF in degenerative intervertebral discs in rats with injured intervertebral discs of the caudal vertebrae. Global Spine J 4: po. 165,2014

27. Haro H, Kato T, Komori H, Osada M and Shinomiya K: Vascular endothelial growth factor (VEGF)-induced angiogenesis in herniated disc resorption. J Orthop Res 20: 409-415, 2002.

28. Gruber HE, Ingram JA and Hanley EN Jr: Immunolocalization of thrombospondin in the human and sand rat intervertebral disc. Spine (Phila Pa 1976) 31: 2556-2561, 2006.

29. Hirose Y, Chiba K, Karasugi T, Nakajima M, Kawaguchi Y, Mikami Y, Furuichi T, Mio F, Miyake A, Miyamoto T, et al: A functional polymorphism in THBS2 that affects alternative splicing and MMP binding is associated with lumbar-disc herniation. Am J Med Genet 82: 1122-1129, 2008.

30. Lawler J, Sunday M, Thibert V, Duquette M, George EL, Rayburn H and Hynes RO: Thrombospondin-1 is required for normal murine pulmonary homeostasis and its absence causes pneumonia. J Clin Invest 101: 982-992, 1998.

31. Tilkeridis C, Bei T, Garantziotis S and Stratakis CA: Association of a COL1A1 polymorphism with lumbar disc disease in young military recruits. J Med Genet 42: e44, 2005.

32. Yang Z, Chen X, Zhang Q, Cai B, Chen K, Chen Z, Bai Y, Shi Z and Li M: Dysregulated COL3A1 and RPL8, RPS16, and RPS23 in disc degeneration revealed by bioinformatics methods. Spine (Phila Pa 1976) 40: E745-E751, 2015.

33. Noponen-Hietala N, Kyllönen E, Männikkö M, Ilkko E, Karppinen J, Ott J and Ala-Kokko L: Sequence variations in the collagen IX and XI genes are associated with degenerative lumbar spinal stenosis. Ann Rheum Dis 62: 1208-1214, 2003.

34. Mio F, Chiba K, Hirose Y, Kawaguchi Y, Mikami Y, Oya T, Mori M, Kamata M, Matsumoto M, Ozaki K, et al: A functional polymorphism in COL11A1, which encodes the alpha 1 chain of type XI collagen, is associated with susceptibility to lumbar disc herniation. Am J Med Genet 81: 1271-1277, 2007. 